\title{
La segunda parte perdida del Coloquio de los perros, de Ginés Carrillo Cerón
}

\author{
Abraham Madroñal*
}

Como es bien sabido, el Coloquio de los perros de Cervantes ofrece un final abierto, en que se promete quizá una segunda parte, en la que Cipión contaría los sucesos de su vida, como lo había hecho Berganza en la primera; pero Cervantes nunca escribió, que sepamos, esa segunda parte; sí lo hizo, sin embargo, un oscuro secretario de la Real Chancillería de Granada llamado Ginés Carrillo Cerón y la incluyó en un volumen misceláneo, que incorpora otras siete novelas y que llevó por título Novelas de varios sucesos (1635). Dicho volumen, del que dio cuenta por primera vez Emilio Cotarelo a las alturas del año 1925 , es único y no lo había vuelto a ver nadie hasta que apareció otra vez citado y extractado en las páginas del magistral Itinerario del entremés de don Eugenio Asensio (1965). Nuevamente el libro desapareció hasta que la buena fortuna, unida al consejo experto de un bibliófilo amigo, lo ha hecho llegar a nuestras manos.

\section{El Autor: Ginés CARrillo CERÓn, ESCRIBANO Y HOMBRE DE LETRAS EN LA GRANADA DEL SIGLO XVII}

Su autor es el abogado de la Chancillería de Granada Ginés Carrillo Cerón, del cual refiere Cotarelo que provendría de las montañas de León y que llegó muy joven a Granada. Él mismo relata en su libro que quedó huérfano muy pronto y fue educado por un tío suyo, al que se muestra muy agradecido, Alonso Pérez Cerón, tesorero de la Inquisición de Valladolid, a quien dedica

* CSIC. 
una de sus novelas. Probablemente sus padres fueron Juan Carrillo y Ana Cerón, porque encontramos lo siguiente en un documento de 1 de enero de 1607: «Venta de Juro en recompensa del oficio de alcalde mayor de la ciudad de Sevilla. Traslado sacado de Fernando de Sotomayor y Cuéllar, escribano público de la ciudad de Sevilla, a pedimiento de Juan Carrillo en nombre de Juan de Hinestrosa, Cárdenas y Ribera, y de doña Ana Cerón, su mujer. Sobre las Alcabalas de la ciudad de Sevilla» ${ }^{1}$.

Se había casado antes de 1600 con doña Ana de Royo o de Arroyo, que de las dos maneras se menciona en los documentos. El 23 de febrero de ese año se bautiza en San Gil a su hijo Diego, apareciendo nuestro escritor como «receptor» ${ }^{2}$. También tuvo una hija llamada Ginesa Carrillo Cerón, que había casado antes de 1630 don Jacinto Ramírez, y de hecho el 17 de mayo de ese año Ginés es testigo del bautizo del hijo de ambos Felipe Santiago ${ }^{3}$. Y otra llamada doña Gracia Carrillo Cerón, que casó en 1629 con el relator de la Audiencia don Pedro Vázquez de Guzmán ${ }^{4}$.

En 1600 Ginés Carrillo Cerón, como heredero de Isabel Ruiz Benítez de Yedros, mujer que fue de Roque de Salvatierra, tiene un pleito con Jerónimo Nieto y Jerónima González de Espinosa, heredera que dice ser de Roque, sobre los bienes dotales, arras y gananciales de Isabel ${ }^{5}$. El 9 de junio de 1616 lo encontramos de nuevo, ejerciendo ahora como administrador de los bienes de diversas personas, según el documento siguiente: «Escritura de poder y lasto otorgada por Ginés Carrillo Cerón, como administrador de los bienes del mayorazgo de Cristóbal Ponce de León, a favor de Francisca Fernández de Córdoba, señora de las Guájaras, para que ésta pueda cobrar de los bienes de Egas Salvador Venegas de Córdoba, futuro conde de Luque, 12.434 maravedíes de un censo que satisfizo la antedicha Francisca».

Carrillo era escribano público ya en 1618, y llegó a serlo de la Cámara de la Chancillería. En ese cargo otorgó una escritura en 1622: «Y el dicho Ginés Carrillo Zerón, por escriptura que otorgó en dicha Ciudad a 10 de Diciembre de 1622 ante Francisco de Tamayo, escribano de su Majestad, en los registros de Gregorio de Arriola, escribano de su número» ${ }^{6}$. Y continuó desarrollando actividades propias de su oficio años después: «Para Ginés Carrillo, notario de la Chancillería de Granada, 40 reales. Gastos de justicia comprometidos por don Gonzalo Vaca, de 1622 a $1625 »^{7}$.

En 1627 encontramos una Real provisión de Felipe IV, librada por el oficio de Ginés Carrillo, para que el vicario de la iglesia de Santa María de la

1. Preparo edición de este libro, en cuyo prólogo aporto los datos de archivo en que se basa esta investigación, aún en curso.

2. Moreno Romera, 2001, p. 287.

3. Moreno Romera, 2001, p. 287.

4. Soria Mesa, 2005, pp. 107-144, la cita de la p. 143.

5. En 27 de diciembre de 1608 es padrino de Gaspar, un esclavo de Juan Garavito, procurador de la Real Chancillería (Moreno Romera, 2001, p. 287).

6. Gil Albarracín, 1996.

7. Balancy, 1999, p. 232. 
villa de Burguillos del Cerro (Badajoz) cese en su pretensión de no pagar los diezmos de granos y semillas a Francisco Diego López de Zúñiga Sotomayor, VII duque de Béjar.

Debió de tener interés por las cuestiones relacionadas con el teatro, así en 13 de agosto:

Leyose petición de Cristóbal de Salazar, como fiador de Francisco González, a cuyo carto está por arrendamiento la casa de las comedias, propio de V. s., en que dice que está preso por mandado de un recetor de Granada por cierta cantidad de marabedises que se le mandaron pagar al secretario Ginés Carrillo por el pleito de Beintijena ${ }^{8}$.

Algunos datos más sabemos, todos relacionados con su oficio; la última referencia que tenemos es que Carrillo Cerón murió en 26 de abril de 1639, según se desprende de los documentos publicados por Bibiana Romero, que lo cita como autor literario y escribano de cámara, el cual «se enterró en esta yglesia [de Santa Ana], en veinte y seis de abril de 1639, era de la parroquia de el Sagrario, enterrose en la capilla de N. ${ }^{a}$ Sra. de la Concepción, que es su sepultura. Por su testamento dicen manda decir ciertas misas en esta iglesia» ${ }^{9}$. Su viuda continuó ejerciendo acciones legales en nombre de su familia ${ }^{10}$.

Es evidente que Carrillo era hombre de alguna fortuna y, desde luego, conectó con los círculos intelectuales de su ciudad: nos consta que en su afortunado carmen de Mira Genil invitaba a los amigos, los cuales se inspiraron en él para dedicarle composiciones poéticas. No tenemos más constancia que la de las propias obras donde se integran, pero es presumible que se formara una especie de academia ocasional en dicho lugar.

A ello obedecen los poemas que le dedican Juan Martínez de Moya, incluido en la propia obra de Carrillo Cerón, o Agustín Collado del Hierro, del cual se incluyen también algunas octavas dedicados a dicha finca que escribió para intercalar en su gran poema Granada (a1635). Junto con ellos los nombres de los dramaturgos Álvaro Cubillo de Aragón y Antonio Mira de Amescua aparecen una y otra vez relacionados con los círculos intelectuales nuestro novelista; pero en ninguna de las obras de estos últimos se encuentra la más mínima referencia a su persona.

8. García Gómez, 1999, p. 204.

9. Moreno Romera, 2001, p. 319.

10. Encontramos un impreso titulado Ana de Arroyo, viuda de Gines Carrillo Zeron, escriuano de Camara que fue en esta Chancilleria. En el pleyto con don Lorenzo de Arroyo, presbytero, vezino y natural de la ciudad de Velez Málaga, y don Gabriel de Arroyo, vezino de la villa de Madrid. Sobre la possession y sucesion del Patrono que fundò el sargento mayor Diego de Arroyo Arguello (Granada, Baltasar de Bolibar, y Francisco Sánchez, 1646), que parece continuar otro titulado El L. don Laurencio de Arroyo y Toledo. en el pleyto con D. Ana de Arroyo su tia, viuda de Gines Carrillo Ceron, escriuano de Camara que fue de esta Real Chancilleria, vezinos de esta ciudad, y con el capitán don Gabriel de la Torre, vecino de la villa de Madrid (Granada, Francisco Sánchez, y Baltasar de Bolibar, 1646. Datos sacados de la consulta del Catálogo del Patrimonio Bibliográfico español. 
Desde luego, las descripciones de Granada reparan inmediatamente en el carmen de Carrillo, igual que lo hacen en el del poeta Pedro Soto de Rojas. Ambos aparecen, uno detrás de otro, en el largo poema Granada, del escritor alcalaíno Agustín Collado del Hierro, que parece que residió en la ciudad algún tiempo, y cuyos versos se intercalan también en las Novelas de varios sucesos que comentamos ahora. Los Anales de Granada, de Francisco Henríquez de Jorquera (obra de mediados del XVII), enumera entre otros cármenes:

El de Hinés Carrillo en la puerta del pescado, a quien llaman miragenil ${ }^{11}$.

Todo parece apuntar que antes de 1630 Ginés Carrillo acogía en su carmen a buen número de personas, intelectuales y de otro tipo, con los que amigablemente departía sobre cuestiones diversas. Sin embargo, no encontramos su nombre en alguna de las muchas enumeraciones de ingenios granadinos de la época.

Carrillo Cerón era hombre acostumbrado a escribir y particularmente gustaba de componer relaciones que tenían que ver con las fiestas celebradas en su tiempo en la ciudad de Granada. Sabemos que compuso, al menos dos, unas Fiestas del santísimo Sacramento. Justa literaria en la parroquial de Santa Ana de Granada, año de MDCXI (impresa en Granada, 1611) y las Fiestas a la Inmaculada Concepción en Granada (1634?), que quedó manuscrita y debe de haberse perdido también, aunque algo de ella nos salvó en las Novelas de varios sucesos.

Por si fuera poco, Carrillo Cerón es también personaje de una obra de otro novelista. Aunque, increíblemente, no lo señala su editor, Emilio Cotarelo, en La mojiganga del gusto (1641), de Andrés del Castillo o Sanz del Castillo, se publica una de las novelas, titulada Pagar con la misma prenda, que sucede en Granada y uno de cuyos personajes es precisamente Carrillo Cerón, que aparece haciendo su papel de secretario en la Chancillería:

En uno de estos aplaudidos pensiles, llamado Miragenil, puso la buena elección de Ginés Carrillo Cerón, Escribano de Cámara de la Cancillería de aquella ciudad ${ }^{12}$.

Carrillo Cerón toma parte en la trama de la novela, en la que un caballero sevillano, don García Tello, pretende casarse con don Ana de Herrera, cosa que consigue al final, en parte por la mediación del propio secretario. Doña Ana era hija de un importante amigo de este, el jienense don Francisco de Herrera, que se encontraba litigando en la Real Chancillería de Granada, y se alojaba en el famoso carmen de Mira Genil de Ginés Carillo.

12. Sanz del Castillo, Mojiganga, 1908. 
No sabemos la relación que tendría con Carrillo Cerón, Andrés Sanz del Castillo, natural de la villa de Brihuega, como él mismo se declara en la portada de su libro, La mojiganga del gusto. Poco se sabe de él, como señala su editor Emilio Cotarelo, y entre esas escasas noticias una de ellas nos señala que quizá vivió en Granada. Pero la novela que nos ocupa, Pagar con la misma prenda, tiene un referente cronológico que la sitúa cerca de los años 1628 y 1629, porque en determinado momento se alude a los «varios festines y juegos de cañas que en Sevilla habían tenido por la canonización de san Pedro Nolasco» ${ }^{13}$.

\title{
LA OBRA: ENTRE LA NOVELA Y LA MORALIZACIÓN
}

La descripción completa de la portada del libro que comentamos es como sigue:

\author{
NOVELAS \\ DE VARIOS \\ SUCCESSOS, EN OCHO \\ DISCVRSOS MORALES. \\ POR GINÉS CARRILLO \\ Cerón, escriuano de Camara de la Real \\ Chancilleria de Granada. \\ DIRIGIDAS A DIFERENTES \\ personas \\ [adorno tipográfico] \\ CON PRIVILEGIO
}

En Granada, en casa de Blas Martinez, mercader,

y Impressor de libros. Año

de 1635 .

El libro se publica en Granada, en casa de uno de los más importantes impresores de la ciudad en su época, Blas Martínez (que imprime libros en el corto intervalo de 1634 a 1636). Aunque de nuestro libro no se da cuenta cuando se trata de este profesional ${ }^{14}$, sí sabemos que le interesaba la mejor literatura del momento, pues en el mismo año que las Novelas de varios sucesos imprime la obra de Martín de Angulo y Pulgar, Epistolas satisfactorias, que trata de la poesía de Góngora y, en particular, le defiende de las objeciones que puso a su poesía el licenciado Cascales en sus Cartas filológicas.

Impresor correcto, aunque sin alardes tipográficos ${ }^{15}$, Blas Martínez imprime también las Novelas de Carrillo Cerón, pero desde que lo hiciera el libro duerme el sueño de los justos. $\mathrm{Y}$, en efecto, perdido y oculto ha permanecido

13. Ibíd., p. 236.

14. López-Huertas Pérez, 1997, I, pp. 176-179

15. Ibíd. 
para los bibliógrafos, historiadores y editores de la literatura española, al menos hasta don Emilio Cotarelo, que dio cuenta de él en el Boletín de la Real Academia Española, en 1925. Después de esa fecha, como he dicho, solo lo ha utilizado Eugenio Asensio en su obra Itinerario del entremés (1965), donde da algunos datos relativos a los actores de entremeses Alonso de Cisneros y Pedro Hernández. Precisamente en el ejemplar único del libro que nos ocupa ha escrito este último poseedor que «fue de Cotarelo, se lo compré a su viuda».

El libro se presenta con cuatro hojas de preliminares sin foliar: la portada, más diferentes escritos legales, erratas, etc. Después sigue la numeración arábiga, que llega desde el folio 1 al $264 \mathrm{v}$, en que consta el colofón, más una hoja final. Se han producido las siguientes erratas en la foliación arábiga: falta el número de folio 34, se escribe 157 (en lugar de 175), 186 (por 189), 129 (por el 192), 121 (por 221), 123 (por 223), se repite dos veces el 225 y falta el 226 y falta el número de folio 241. Los pliegos se marcan también con las signaturas A-Z[8] y Aa1-Kk[8]. El libro ha perdido su encuadernación original y se presenta hoy encuadernado en piel, seguramente por obra de don Emilio Cotarelo.

Según Cotarelo, Carrillo Cerón compuso estas novelas en 1625, fecha del Donativo a que alude el mismo autor en el prólogo y dedicatoria de sus obra. Señala Cotarelo que «este donativo forzoso se cobró en 1625, empleando para ello los oidores y otros jueces» ${ }^{16}$, obligando para ello a suspender los pleitos en la Chancillería, con lo cual nuestro escribano ni tuvo trabajo ni ganancias.

Acaso intentó publicar inmediatamente lo que había escrito; no lo sabemos, pero lo cierto es que se encontró con la prohibición de imprimir novelas y comedias en Castilla, de manera que tendría que guardar la obra en un cajón de su escritorio. Es evidente, como dice también el estudioso y descubridor de nuestro libro, que la obra se fue puliendo, al menos hasta 1632, en que la aprueba Lope y Carrillo inicia el trasiego habitual para conseguir licencias y privilegios. Tres años tardaría en salir a la luz pública, lo cual quizá impidió que le llegara a su aprobante, Lope de Vega.

La obra combina diversos tipos de relato, como también ocurre en las Ejemplares cervantinas: por un lado están las novelas que suceden en ciudades españolas como Sevilla, Granada, Valladolid y otras; por otro, las que tienen lugar en lugares distantes y exóticos, como es el caso de Hungría, Polonia, Inglaterra, etc. En las primeras, los personajes tienen nombre y apellidos, incluso nos atreveríamos a decir que responden a personas de carne y hueso, que protagonizan sucesos reales, tal y como declara el propio Carrillo en la dedicatoria de la primera. Especie, pues, de novela en clave, a veces muy poco disimulada, como también ocurre en las que incluye la Mojiganga del gusto de Sanz del Castillo, donde aparece el propio Carrillo Cerón como personaje.

16. Cotarelo, 1925, p. 644. 
El caso de Carillo no es, desde luego, el único entre los novelistas seguidores de Cervantes, especialmente de sus Ejemplares; tenemos también el ejemplo temprano de Francisco de Lugo y Ávila, en cuyo Teatro popular (1622) sigue la senda trazada por el alcalaíno y lo escoge como fuente concreta en alguna de las novelas que componen dicho libro: la titulada La hermanía es un trasunto de Rinconete, entre otras obras.

También Carrillo Cerón era, sin duda, un buen lector y un fino catador de la mejor literatura de su tiempo. Confiesa él mismo en su libro que no leía otra lengua que el castellano, pero eso evidentemente no era obstáculo para apreciar a los buenos cultivadores de las bellas letras en esa lengua. Fue devoto de Lope, pero también de Cervantes, del que dice unas palabras elogiosas a propósito de sus novelas, como pocos contemporáneos habrían escrito:

Miguel de Cervantes Saavedra, aquel prodigio de ciencia y que en esta materia se aventajó a todos ${ }^{17}$.

Y en la dedicatoria de la novela concreta, le dice a Lope:

No sé cómo me atrevo a dedicar a v. m. esta humilde novela que intitulo Segunda parte de Los perros de Mahúdes, que hizo el insigne Miguel de Cervantes Saavedra, siendo v. m. el Apolo, el oráculo, el Fénix, el Virgilio de nuestros tiempos.

No sabemos cómo le sentarían a Lope, particular enemigo de Cervantes, al menos desde principios el XVII, estas palabras, sobre todo después de haber escrito él las llamadas novelas a Marcia Leonarda, publicadas en La Filomena (1621) y La Circe (1624); pero a las alturas de 1632 es muy probable que el Fénix solo sintiera conmiseración por el autor del Quijote, que tiempo atrás había sido su detractor.

El caso es que Carrillo Cerón es un admirador de Cervantes y un fiel lector, al menos, de sus Novelas ejemplares, de tal manera que concibe la idea de componer ocho novelas, en una de las cuales sigue la senda del genial ingenio alcalaíno, y lo hace porque este había prometido segunda parte, pero no la había llegado a publicar. Me refiero, claro está, al Coloquio de los perros.

Pero Carrillo no era ajeno tampoco a los otros noveladores posteriores a Cervantes, seguramente era un buen lector de novelas y no ignoraba que después de las del autor de las Ejemplares otros nombres habían continuado por esa senda narrativa, nombres como Alonso Jerónimo de Salas Barbadillo (1614, 1620), Juan Cortés de Toledo (1617, 1620), Diego de Ágreda y Vargas (1620), Francisco de Lugo y Ávila (1622), Gonzalo de Céspedes y Meneses (1623), Juan Pérez de Montalbán (1624), Tirso de Molina (1624), Juan de Piña

17. Carrillo Cerón, Novelas, 1635, prólogo. 
(1624, 1627, 1628), José Camerino (1624), Alonso Castillo Solórzano (1625, 1626, 1627, 1629, 1631, 1634), Miguel Moreno (1628), Pedro Castro Anaya (1634) y, entre otros, el ya citado Lope.

Llama la atención, por la cercanía de su número y de su título, la recopilación de Montalbán Sucesos y prodigios de amor en ocho novelas ejemplares (Madrid: Juan González, 1624). Carrillo desprecia el número de seis novelas que escogen otros, como es el caso de Céspedes en sus Historias peregrinas y ejemplares (Zaragoza: Juan de Larumbe, 1623), que se ofrece como primera parte, o el de Cortés de Tolosa, ya citado. Tampoco sigue a su modelo y publica una docena, como también había hecho Diego de Ágreda y Vargas en sus Doce novelas morales, útiles por sus documentos (Madrid: Tomás Junti, 1620).

Pero la relación con la recopilación juvenil de Montalbán, la citada Sucesos y prodigios de amor en ocho novelas ejemplares (1624), parece más estrecha porque ofrece justamente el modelo que escogerá Carrillo: se trata de ocho relatos independientes, precedidos de una dedicatoria a un personaje destacado, uno de los cuales es - igual que en el caso de nuestro autor- su maestro, Lope de Vega. Es cierto que Montalbán se pierde mucho menos en digresiones sobre cualquier asunto que Carrillo Cerón, pero igualmente su temática es variada (tiende desde el relato de corte bizantino a la narración de cautivos $)^{18} \mathrm{y}$, quizá por la juventud del autor que era todavía estudiante en Alcalá, se desliza por peligrosos caminos, que hicieron que su recopilación cayera en las garras del tribunal del Santo Oficio por el final escabroso de una de sus novelas.

Carillo Cerón publica ocho y promete segunda parte, si estas tienen buen acogida. No debieron de tenerla, pues a la vista está que no nos ha llegado la prometida segunda parte y seguramente algo tuvo que ver en ello el contenido comprometedor de estas ocho novelas, que se permiten enjuiciar determinadas premáticas o censurar costumbres de la sociedad de su tiempo (el abuso de los tratamientos, también asunto de otra premática de aquellas fechas). Acaso habría que buscar también alguna explicación literaria: ya advertía Cotarelo que nuestro coloquio «cede y queda muy por bajo del de Cervantes en cuanto al estilo; pero el fondo es más variado y los episodios más vivos y rápidos que en Cervantes» ${ }^{19}$.

No nos parece hoy que ni por la viveza ni por la rapidez se puedan comparar estas novelas a las cervantinas, aunque sí compartimos con ese antiguo poseedor de este libro, que fue don Emilio Cotarelo, que la continuación de Carrillo es «en resolución, muy entretenida y amena», incluso - añadotiene importantes elementos literarios para tenerla en cuenta, no solo por las ricas noticias que aporta sobre esos dos grandes actores de entremeses que fueron Cisneros o Pero Hernández, también por los múltiples episodios que intercala: cuentecillos cuya difusión no se conocía del todo (con el de «Pitas 
Payas»), descripciones pintorescas o costumbristas de fiestas como la Santa Verónica o la romería de la Virgen de la Cabeza, en nuevo testimonio que hasta ahora no se había utilizado, etc.

\section{OCHO NOVELAS EJEMPLARES}

También como profesión de disciplinantes, en frase de Tirso de Molina, se presentan estas ocho novelas, una seguida de otra, sin más tema unitario que la repetición de algunos lugares donde suceden los hechos.

La que abre el libro es la novela El agraviado de sí mismo, de paradójico y teatral título, se sitúa en Sevilla, y en la dedicatoria de la novela se advierte que el suceso que cuenta sucedió realmente. Los hechos son los que podrían aparecer en una comedia de capa y espada de su admirado Lope de Vega: Francisco de Alvarado, natural de Trujillo, ha quedado huérfano tempranamente y duda entre ir a estudiar a Salamanca o probar fortuna en Indias; una amigo de su padre le da cartas para Sevilla y acaba embarcándose hacia América para agrandar la hacienda del mercader Carlos Vitelo; a la muerte de este, Alvarado se hace rico y obtiene el cargo de capitán. Decide volver a Sevilla para casarse, y cuando va a casa de su amigo Alonso de Barrientos, una mujer (que después sabemos que es doña Claudia) le hace pasar a su casa, confundiéndolo con un tal don Diego Altamirano, en cuyo nombre la goza. Ella le dice que está de acuerdo con su casamiento (contra la opinión de sus tíos) y le da un agnus dei y él una banda.

Los tíos de doña Claudia, que son amigos de Barrientos, le proponen a Alvarado que se case con ella, pero la mujer dice que prefiere ser monja porque se da cuenta de que no ha estado con don Diego, ya que este le había dicho que no había sido él el que estuvo con ella esa noche. Al final, concierta en casarse con Alvarado, mientras su prima, doña Juana, se casa con don Diego, que había puesto los ojos en ella al enterarse del episodio de doña Claudia. Por fin se organizan las dos bodas, y los unos son padrinos de los otros; doña Juana le dice a doña Claudia que se ponga la banda que le habían regalado, pero ante su negativa se la pone la propia doña Juana, ello provoca la confusión de Alvarado, que piensa que se ha acostado con doña Juana y en su noche de bodas se da cuenta de que doña Claudia no es virgen y prefiere callar. Marchan las dos parejas al alcázar de Sevilla, lo que provoca una digresión del autor sobre las flores, cuadros, escudos, etc. que contiene. Allí se organiza un juego de apuestas que genera tal confusión que doña Claudia piensa haberse acostado con un criado, porque el agnus dei aparece en sus manos. Al final, doña Juana confiesa que la banda no es suya, sino de doña Claudia; hablan esta y Alvarado y confiesa la verdad: quería acostarse con don Diego para forzar la boda, pero no sabe con quién compartió lecho. A Alvarado le interesa conocer si lo sabe alguien más y pregunta a don Diego si había llegado a mayores con doña Claudia y este le dice que no, porque sabía lo que había 
pasado esa noche. Y, como nadie más sabía nada del asunto, todos quedan casados y felices y el mayorazgo de Alvarado se fue acrecentando, hasta ser de los más ricos de Sevilla.

La segunda lleva por título Cada loco con su tema, y nos parece una de las novelas más logradas de la presente recopilación. Cuenta el caso de Clorinardo, príncipe de Macedonia, que se ha enamorado de la hija del Gran Soldán de Persia, Aureliana, y cuyo hijo y heredero, el príncipe Floriandro, convoca una justa en su corte de Babilonia para entretenerse. Vence a los diferentes caballeros que se presentan de varias nacionalidades y un caballero aventurero que no se descubre y todo el mundo piensa que es el Príncipe de Macedonia, no solo le vence, sino que lo mata por accidente (la lanza se le clava en el ojo) y se ve obligado a huir.

El Gran Soldán promete recompensa a quien se lo traiga vivo o muerto y él escapa a la campaña, cerca de la ribera de un arroyo. Justamente en él quería suicidarse un pastor que se encuentra, Albano, el cual cuenta su historia: enamorado de Clórida, su padre, Danteo, la dio en matrimonio al rico Doristo. Ya casados, una día que este dormía en el campo, le tiró una roca y lo mató, desfigurándole por completo. El príncipe le propone que le vista con sus ropas y anillo, y lleve el cadáver al Gran Soldán, diciendo que él es su hermano loco, Meliandro. Así el príncipe consigue encontrase con la princesa y el soldán y les dice verdades entreveradas con locuras, en las que finge ser el príncipe y estar enamorado de la princesa, para regocijo de todos. El Gran Soldán repite continuamente: «Cada loco con su tema». De noche, se viste de príncipe y le canta a la princesa canciones alusivas, entre ellas un soneto de Padilla; de pronto se reciben cartas del rey de Macedonia, que declara la guerra por haber dado muerte a su hijo, cuando no tenía culpa, invade el reino de Persia y llega a cercar Babilonia. Reta al soldán para que un caballero de cada bando dirima la cuestión en una justa y el de Persia nombra a su condestable, mientras el de Macedonia al duque Fortimán. Pero el loco, que quería combatir, llama con gran secreto al condestable, se descubre y le pide que le permita ocupar su puesto. Vence en la batalla, se quita el casco y descubre a su padre que está vivo. Se casa al final con la princesa, entre grandes demostraciones de amistad de las dos naciones.

La tercera se titula El más constante. La acción sucede ahora en Granada, en esa ciudad Ricardo Peralta, hijo de padres nobles, se dedica al estudio, pero también se divierte como joven que es. Se ha enamorado de Dorotea, noble joven hija del licenciado Mondragón, que antes de corresponderle prefiere meterse monja. Se produce una digresión sobre Granada y, en especial, sobre el propio carmen de Carrillo, que se llama Mira Genil y se copian dos poemas ajenos, de Martínez de Moya y Collado del Hierro, que lo describen. El padre de Dorotea es proveído para una plaza de asiento en la corte y tiene que trasladarse a Madrid. Se produce en este momento una digresión sobree los pretendientes a cargos de justicia en la corte y se critica su mala actuación en los respectivos lugares para donde obtienen el cargo. Carrillo confiesa que es testigo de vista de lo que dice (f. 82v). 
Mondragón y su hija salen en un coche para Madrid y Ricardo decide marchar a Salamanca para terminar sus estudios. Cuando llega a la venta de san Andrés, un criado llega corriendo y advierte que unos bandoleros han asaltado el coche del licenciado y su hija, cerca de Santisteban. Ricardo les auxilia y hace huir a los bandoleros y Mondragón, que no le reconoce por la oscuridad de la noche, cuenta cómo fue alcalde mayor de Córdoba, antes de ser abogado de la Real Chancillería de Granada. Cuando el joven declara quién es, Dorotea empieza a mirarle bien, aunque no para esposo suyo. Finalmente continúan camino hacia Madrid, donde entran justo en el tiempo en que llega el nepote del papa Urbano VIII, y se hallan en el recibimiento que le hizo Felipe IV (cosa que ocurrió en 1626). Ricardo continúa viaje hacia Salamanca y ya en aquella ciudad se acerca a unas damas, que pasaban la tarde cerca del Tormes; pero el gallego Diego Sarmiento, que las festejaba, le reta por ello; Ricardo pelea bien, pero les hacen amigos para no tener que responder ante la justicia. Ricardo, en su fuero interno, quiere vengarse de él y urde una estratagema: invita a jugar al hombre a unos amigos en su posada y se produce una digresión: don Francisco de Rojas (nombre que coincide con el del dramaturgo toledano, estudiante en dicha universidad por esos años) explica en qué consiste dicho juego. Ricardo dice que le duele la cabeza, se va a acostar en su cama, pero en realidad se va por una puerta trasera a esperar a Sarmiento en su casa, y cuando sale, le tira unas estocadas que parecen dejarlo herido de muerte. Vuelve corriendo a su posada, se reincorpora a la partida. Cuando la justicia busca al ofensor, detiene a Ricardo, que consigue librarse de la cárcel por su coartada y porque no muere Sarmiento de dichas heridas. La acción vuelve ahora a Madrid, donde Mondragón ha sido proveído como teniente de corregidor de Valladolid.

Ricardo regresa a la corte, justo en la víspera de la romería del Ángel, en la que se suele pasar la Puente segoviana para acudir a dicha ermita. Justo cuando van a ella, encalla el coche donde va Dorotea y Ricardo, sin que ella sepa que allí está su galán, la salva de que la arrastre la corriente del Manzanares. Se produce de nuevo el agradecimiento de la dama, que se lo cuenta a su padre. Este le invita a asistir en Valladolid a la ceremonia de la entrega de la vara y cuando van de camino y suben el puerto de Guadarrama, Dorotea cae de la caballería que la transporta y queda enganchada por su ropa de unos arbustos. Otra vez Ricardo tiene que salvarla, en una situación que no deja de ser cómica, porque se produce la turbación de este al encontrase a su dama boca abajo, descubriendo más parte de su cuerpo de la que la honestidad permitía que se viera. La dama, rendida ya por esta tercera muestra de rescate, ruega al joven que la pida en matrimonio a su padre. Al seguir el camino pasan por Villacastín y llegan a la ciudad del Pisuerga, donde los jóvenes se casan, mientras el corregidor de la ciudad hace de padrino de bodas, justo cuando el cómico Tomás Fernández representa una famosa comedia. Nos cuenta el novelista para terminar que Ricardo fue un gran letrado.

Más vale saber que haber es el título de la cuarta novela, una historia ingenuamente desarrollada que pretende demostrar lo que dice su título: 
más vale conseguir una buena educación que todas las riquezas del mundo. La tesis se demuestra contando la oposición vital entre dos amigos, Obregón y Juan de Ochoa, que en determinado momento deciden qué hacer con su vida. El primero quiere ir a estudiar a Salamanca, mientras Ochoa prefiere irse a Indias, para hacerse rico. Se emplazan dentro de doce años en Madrid para comprobar quién ha acertado con la decisión. Mientras uno marcha a la Universidad citada, el otro sale de Madrid en compañía de un caballero noble, que le lleva como criado, con quien hace el camino. En él se encuentran con dos caballeros heridos, naturales de Alcaraz: el joven Carlos y su padre, que cuentan que han sido atacados por los parientes de la novia de Carlos, porque este - aconsejado por su padre - había decidido dejarla, ya que no tenían la misma «calidad». En este momento se produce una digresión sobre los matrimonios sin el consentimiento paterno.

Al final, Ochoa y su señor llegan a Granada, donde vive un hermano de este. Se produce ahora una digresión en la que se describe la ciudad y, especial y pormenorizadamente, el túmulo levantado a la Virgen, en cuya colocación tuvo que ver Carrillo, según confiesa. Leemos los rótulos que mandó poner la ciudad y en ellos los años de 1631 y 1634. Después, Ochoa embarca con su caballero hacia Indias, porque este tiene el regimiento de Potosí. Cuando están a punto de cumplirse los doce años que se había dado de plazo con su amigo, la acción cambia ahora y se enfoca hacia Obregón, que se había hecho catedrático de Salamanca y vuelve a Madrid con sus criados; Ochoa va hacia Madrid también, pero pobre y enfermo de melancolía: su noble señor le había hecho alguacil en Indias y consiguió hacer fortuna allí, pero al embarcar para España, una tormenta sepultó toda su riqueza en el mar. La buena amistad de Obregón hace que este socorra a su amigo, que consigue también establecerse en España y obtener una posición desahogada.

La quinta se titula Las tres joyas y no es más que un simple cuento maravilloso convertido en novela por gracia y obra de Carrillo Cerón. En él ocurre que la reina de Inglaterra está sola y su corte le aconseja que se case, aunque ella no quiere. Finalmente se decide a hacerlo y se hace retratar, para que puedan verla los diversos pretendientes en las cortes extranjeras. Su retrato llega a Francia, Hungría y también a España, donde cada uno de los tres hijos de los reyes decide pedir permiso uno a uno a sus padres para viajar a Inglaterra y disputar la mano de la reina. Esta, a cada pretendiente que va llegando le hace encerrar en una mazmorra subterránea, como así le ocurre al príncipe heredero de España. Entonces el segundo hijo corre el mismo camino y la misma suerte que su hermano mayor. Le toca el turno al tercero, que después de obtener el permiso, marcha como caballero aventurero y al llegar a Inglaterra se pierde por un bosque y se encuentra casualmente a un ermitaño que resulta ser tío suyo, el cual vive en una ermita velando la tumba de su amada. El ermitaño le da un consejo al joven: si sigue adelante, se encontrará con tres magas que querrán acostarse con él; pero debe evitarlo diciendo que ha hecho una promesa. 
En efecto, al llegar al castillo de las tres mujeres, que en realidad resultan ser tres castillos, evita dormir con ellas y obtiene un objeto mágico de cada una: un mantel, en el que aparece la comida que se desee; un frasco, en el que igualmente aparece el vino que se quiera, y una cítara, que hace bailar a quien la oye. Cuando llega ante la reina y corre la misma suerte que los demás, da de comer y beber a todos los presos de la mazmorra gracias a sus dos primeros objetos mágicos, y después les hace bailar y también a sus carceleros (una dueña y otro). Al enterarse la reina, le pide los tres objetos y él se los promete, si ella es capaz de contestar «no» a tres preguntas que le formule. Por ese medio, con la habilidad de preguntarle cosas a las que tiene que responder negativamente, consigue liberar a todos los presos y también que la reina se abrace a él, momento en que se da cuenta de que se casará con ella. Así sucede, y termina felizmente la novela.

La sexta novela, La inocente culpada, es una historia exótica que sucede en el reino de Polonia, allí la reina Matilde, hermana del rey de Suecia, convive con el duque Federico, grande del reino, que no tenía más que una hija, Clorinarda, la cual está enamorada del conde Rodulfo, «hombre altivo pero inquieto». Cuando sus padres la prometen en matrimonio con otro noble, ella escapa con su enamorado llevándose sus joyas; pero él la abandona en un bosque después de robarle lo que llevaba. Allí, bajo disfraz varonil y haciéndose llamar Febo, conoce al pastor Sireno, que le cuenta su desastrada historia de amor con la pastora Lucina, la cual le ha abandonado por otro pastor más rico. Como en la corte, todos piensan que Rodulfo ha raptado a la joven, el conde decide marchar a Francia, cuyo rey era deudo suyo.

Un buen día, el rey de Suecia viaja en barco hacia Polonia y se encuentra casualmente con Febo, y decide llevarlo con él, pero al llegar a la corte la reina Matilde le coge afición al joven; otro criado denuncia que hay lascivia en esa atracción de la reina, razón por la cual el rey da muerte a su esposa y cree que también a Febo, pero este huye justamente a casa de sus padres y les revela su verdadera identidad. Cuando el rey de Suecia reta al de Polonia por haber dado muerte a su hermana, Clorinarda, ya como mujer, explica todo se casa con el conde Rodulfo que había acudido a Polonia comisionado por el rey de Francia y el de Polonia se casa con otra hermana del rey sueco.

La séptima y penúltima es Los perros de Mahúdes, o segunda parte del Coloquio de los perros, de que tratamos más abajo. Y cierra el libro la titulada La selva de Hungría, que es una novela inverosímil y atropellada donde las haya que cuenta las peripecias de Fortimán, que está a punto de suicidarse arrojándose al Danubio, y Flora, que lo detiene y le obliga a darle cuenta de sus infortunios. Como se ve, comparte con Cada loco con su tema el curioso nombre de Fortimán, aquí protagonista, que es hijo del duque Astolfo, hermano del rey Matías de Hungría, que no había tenido hijos con la reina Alfreda. Fortimán, a quien su padre manda a la corte de su hermano para formarse, es requerido de amores por la reina y, como no había accedido a sus deseos, porque ama a la bella Aurora, se ve obligado a salir de la corte para salvar la vida, mientras contempla cómo su amada se casa con otro hombre, el prín- 
cipe de Transilvania, porque así lo decide la reina. Como tampoco Fortimán accede a su lascivo deseo, ella le dice al rey que la pretende amorosamente y lo meten preso en una torre, pero consigue escapar a la selva mintiendo a la reina, por cuanto le dice que quiere amarla. Por su parte, Flora, que en realidad se llama Casandra, no le dice a Fortimán que es su hermana y tampoco este parece adivinarlo, y corresponde al joven contando su propia historia: se dice hija del duque de Aquitania, tenía un hermano que enviaron con el rey de Suecia y su padre casó de segundas con una duquesa, la cual tenía un hermano llamado el conde Mauricio; Flora estaba enamorada del marqués de la Floresta, pero se ve requerida de amores por el conde Mauricio; ella se las ingenia para que su amado entre disfrazado de mujer en la corte y convive con ella un tiempo, pero quedará embarazada de él y en el momento del parto queda con el padre de su hijo para huir, sin embargo este no aparece y se ve obligada a parir, ayudada por precisamente su pretendiente, el conde Mauricio, al que le deja al recién nacido.

Nada más dar a luz se escapa también de la corte húngara y va a parar a la selva, donde se encuentra con Fortimán, sin saber qué había sido de su amado, porque no estaba donde se suponía que le tenía que encontrar, ni de su hijo. Todos creen que el conde Mauricio, que llama Tribaldos al niño igual que él, es el padre de verdad y que se ha deshecho de ella, de manera que lo acusan y tiene que huir para salvar la vida. Justamente llega a la selva y allí se encuentra a los dos hermanos, mientras canta un doliente poema. Todos declaran quiénes son y él dice ser hijo del conde Palatino del Rin. Tenía un hermano mayor, que heredaría a su padre, pero su madre - la condesa Matilde - le prefería a él y por eso su padre y hermano se confabularon para matarlo y su madre le hace escapar a Bullón, donde estaba casada su hermana (madrastra de Flora). Por fin, Flora y Fortimán se descubren, también entre sí y todos quedan muy felices. De pronto viene un barco por el Danubio en el que viaja el marqués de la Floresta, que también cree que su amada le ha sido infiel con el conde de Tribaldos, pero con él viene el criado de Flora, Sireno, que desciende del barco, aunque el de la Floresta no quiere acercarse, por creer que Flora y Tribaldos están juntos. Cuando todo se aclara, se abrazan todos. Sireno cuenta que murió la reina Alfreda, exculpando en carta a Fortimán, y todos se embarcan para a ir a Hungría, justo cuando oyen gritar a dos mujeres: son la duquesa de Bullón (madrastra de Flora) que había huido con el caballero Arnaldo, por haber sido condenada a muerte por pensar el duque había tenido que ver en todo el infortunio anterior, y su criada Calidora. Arnaldo la había requerido de amores e intentado forzar (y su criado Renato a Calidora), pero gracias al socorro de Fortimán se había desbaratado el intento. Todos embarcan de nuevo. En Hungría, había fallecido el rey y Fortimán de convierte en gobernante, mientras escribe a su padre para que venga a hacerse cargo del reino, este contesta que está mejor en manos de Fortimán, porque él es ya muy viejo. Entre tanto, también había muerto el príncipe de Transilvania, dejando viuda a Aurora, a quien reclama Fortimán como esposa y reina de su estado; por su parte, Federico, príncipe del Palatinado, había muerto de una caída 
de un caballo y Tribaldos le tiene que suceder, el cual se casa también con Teodora, hermana del Transilvano. Para que no queden cabos sueltos como en cualquier comedia palatina que se precie, Sireno se casa igualmente con la criada Calidora.

\section{LA SEGUNDA PARTE DEL COLOQUIO DE LOS PERROS}

Por fin, la segunda parte de El coloquio de los perros, que ocupa, como he dicho, el penúltimo lugar de la colección. Básicamente, la novela responde al argumento que se encuentra en la cervantina que le sirve de fuente: Cipión se limita a contar su vida durante otra noche en el hospital, correspondiendo así con lo que ha hecho en la noche anterior su compañero Berganza y cumpliendo con las palabras que se leen al final de la narración cervantina. Para mayor cercanía con esta, el alférez Campuzano y el licenciado Peralta siguen cumpliendo en esta segunda parte la función que tenían en la primera, por cuanto el segundo coloquio de los perros también se presenta como un papel escrito que guardaba en su cabeza el alférez.

De esa manera, la estructura seguida por Carrillo es relativamente similar a la que emplea Cervantes en la primera parte: patria de Cipión, proceso de aprendizaje con sus primeros amos (mondonguera y jifero, pasteleros, pintor de Toledo), madurez (clérigo de Cubas) y final (estudiante de Villacastín). Este proceso de aprendizaje permite a Cipión burlarse de algunos personajes y no ser mero espectador de las burlas de estos: así ocurre, por ejemplo, con el caballero portugués que desprecia a una mujer pobre y pedigüeña, al que hace caer; así ocurre igualmente con el clérigo de Cubas, burlado ahora por su nuevo amo, el estudiante. El final para este consiste en entrar en religión y se corresponde con la llegada de Cipión al Hospital vallisoletano.

La luz de la mañana termina el tiempo del relato de los perros y el alférez y el licenciado salen a pasear por Valladolid para cerrar la novela.

Pero será conveniente que especifique con detalle su estructura:

Preliminar en que hablan el alférez Campuzano y el licenciado Peralta: el alférez promete contar la segunda parte.

Coloquio de Cipión y Berganza.

Cipión da detalles de su vida

Interrupción del alférez y comentario de lo anterior, diálogo con Peralta.

Continuación del coloquio

patria de Cipión

primer amo: la mondonguera y su marido el jifero

defensa de los escribanos

crítica de la premática de los precios 
La Santa Verónica de Jaén

Cuentos de los ladrones que roban el jumento

segundo amo: los pasteleros que van a Andújar

crítica a los pasteleros

fiestas de Santa María de la Cabeza

cuento ridículo de los dos lisiados

romance a la imagen y santuario

tercer amo: el pintor de Toledo

el cuento de Pitas payas con la mujer del pintor y su oficial

cuento de los tres papagayos

cuarto amo: el clérigo de Madrid

crítica o arbitrio de los tratamientos

cuento del caballero portugués

cuento de los pasteleros de Murcia que trocaban sus mujeres

peligros de la corte

contacto con el estudiante de Villacastín, camino de Toledo

alojamiento en Cubas, en casa del clérigo

dichos de comediantes

Cisneros

Pero Hernández

el clérigo perdido por vocablos nuevos

burla del clérigo por el estudiante

quinto amo: el estudiante de Villascastín

encuentro con el fraile de san Francisco que pondera su modo de vida

cuento del pretendiente a un hábito en su orden

llegada a la venta

el ventero les ayuda a pasar el puerto

llegada a Villascastín: el estudiante anuncia a sus padres que entrará en religión

Acaba la narración con la marcha del fraile y la llegada del perro a Valladolid, en cuyo Hospital le recibió Mahúdes.

Llega la mañana y con ella acaba se acaba la plática, aunque la vida de Cipión había terminado ya. El licenciado Peralta recuerda un dicho de Felipe II para proclamar la superioridad de Madrid frente a Valladolid.

Como se ve por la simple enumeración expuesta, la obra tiene una fuerte carga crítica contra la situación social: Carrillo critica prácticamente a todos los estados que se encuentra, desde los jiferos y mondongueras, hasta los maridos consentidores, pasando por los pasteleros que venden gato por liebre, conchabados con los poderes políticos correspondientes o los falsos pobres, los clérigos amancebados y perezosos. Pero también resultan criticadas determinadas costumbres sociales, como lo que llama con cierta gracia «orgullo del 
suevo», es decir, el abuso de los tratamientos como el «don» que impide algo tan importante en la España de su tiempo, como es el que se pueda trabajar en cualquier tipo de oficios, sin que el sentimiento de pertenecía a un estamento superior se lo impida a la persona en cuestión.

La distinción entre sátira lícita o ilícita, o lo que es lo mismo, entre crítica y murmuración, parece desarrollarse en un escrito casi contemporáneo, que intenta establecer la barrera entre el vejamen (no aceptable) y la sátira (aceptable). Dice así Miguel Martel en un Vejamen universitario pronunciado antes de 1653:

El dezir que el juez admite el cohecho, que el escriuano quita o añade en la causa conforme se le paga, que el médico es ydiota y que en el sortijón y guantes sólo tiene la ciencia y otras cossas parecidas a éstas no son sátira porque no consiguen el fin para que las inuentaron los maestros dellas. Son solamente chistes maliciosos que encierran en sí tantas mentiras como letras. Esto sí que es fácil; yo apostaré que le pareze lo más dificultoso por no acertar en nada ${ }^{20}$

Chistes, como los que se introducen en nuestra obra, que no llegan nunca a las personas, sino que se quedan en los vicios. Continuamente, Berganza recuerda a su compañero Cipión que no tiene que murmurar, que tiene que pararse en la crítica de los vicios sin llegar a particularizar en las personas que caen en ellos, tal y como ocurría también en la primera parte cervantina que sirve como modelo.

Pero Carrillo se permite censurar también disposiciones legales como la famosa premática de los precios que había traído la ruina a determinados sectores comerciales y había servido justamente para lo contrario de lo que pretendía: encarecer todavía más los productos cuyo precio, supuestamente, pretendía regular. Y, como no podía ser de otra manera, reacciona incluso contra ciertos tópicos de la época, como el que critica a los escribanos, su propio grupo, que bajo capa de cobrar indebidamente, lo que hacían era mantener los mismos aranceles que se venían aplicado desde mucho tiempo atrás.

Carrillo Cerón parece querer «cristianizar» la novela cervantina que le sirve de modelo, y Cipión no cuenta sucesos relacionados con brujas o hechiceras, sino que se demora en la descripción de la fiesta y el santuario de Nuestra Señora de la Cabeza, una descripción sin duda políticamente correcta que limaba posibles suspicacias.

En suma, un pobre epígono de Cervantes, pero una interesantísima obra por muchas y diversas razones, perdida hasta ahora, pero encontrada al fin, y que merece que se conozca en los términos exactos en que se escribió para entender la difusión y la interpretación que la novelita cervantina tuvo en su época y para aportar un dato más sobre el aprecio que por Cervantes sintieron algunos de sus contemporáneos. 

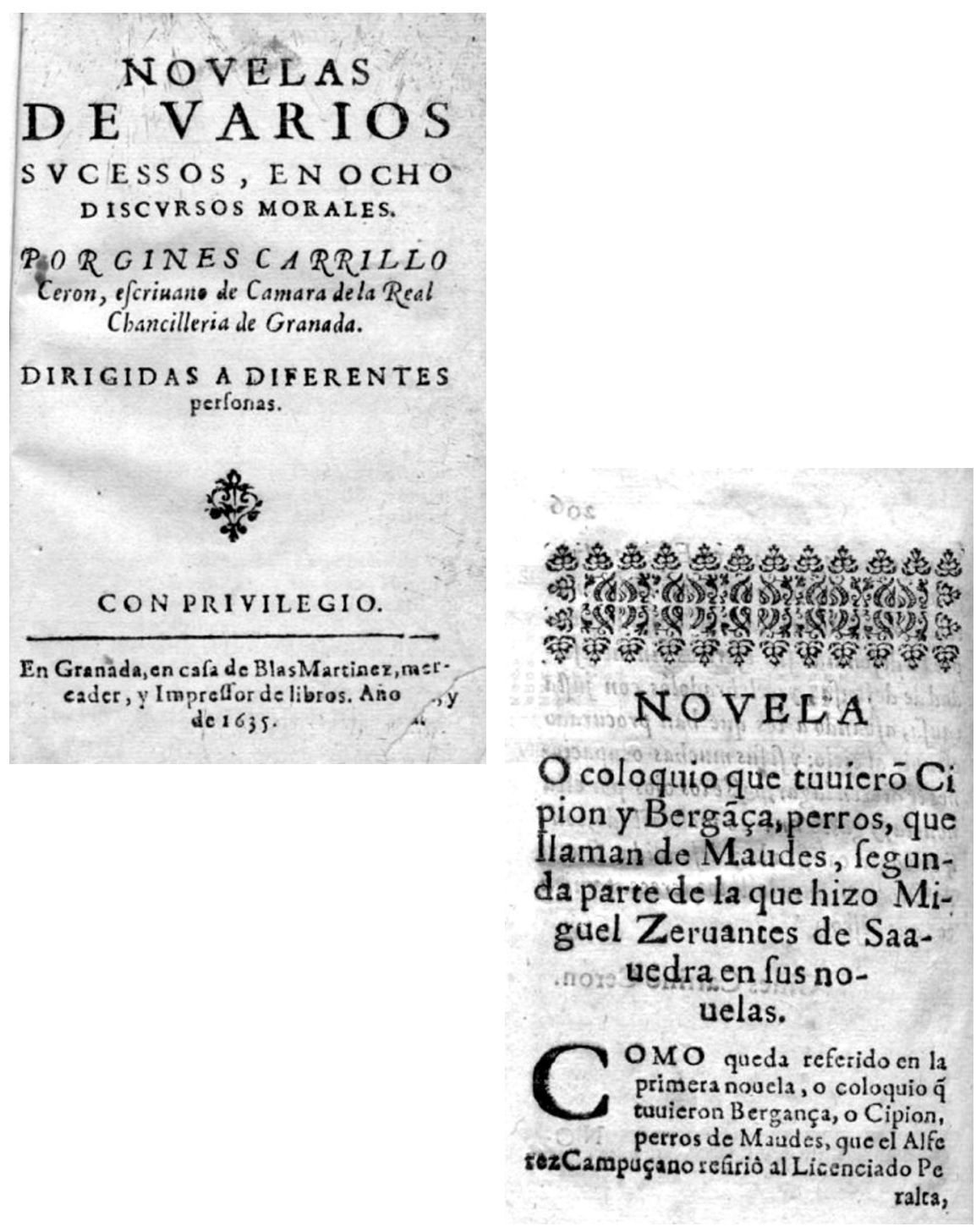


\section{TABLADELAS}

NOVELAS DESTE LIBRO.

E L agrauiado de fi mefmo, a don Diego Hur: tado de Mendoza, Conde de la Orçana, Afsif tente de Seuilla, del Abito de Santiago.

Cada loco con fu tema, al Dotor don Gafpar de Sazuedra, del Confejo del Rey N. feñor, Oy * dor en la Real Chancilleria de Granada.

El mas conftante, a don Iuan Perez de Lara, Abo gado de la Chancilleria de Granada.

Mas vale faber, que auer, al Licenciado don Iuan

Ruyz de Sao Cebrian, Vifitador general de la villa de Madrid, y fu partido.

Las tres joy as, a A lófoperez Ceron, Teforeto de la Inquificion de la cindad de Valladolid.

La inocente culpada, a don Luys Yańez de Montenegro, Familiar del Săto Oficio de la Inqquificion,Regidor de la villa de Madrid, contino de la cafa de Caltilla, y oficial principal dela Secretaria de la Camara.

Los perros de Maudes, a Frey Lope Felix de Vega Carpio, del Abito de San Iuas, Familiar del Santo Oficio de la Inquifion, y Filcal de la Camara Apoitolica.

La felva de Vngria, al Dotor dó InāBautifta dela Rea, del Confejo del Rey N. feńor, y fu Oydor que fue en la Real Chancilleria de Granada, y oy Fifcal en el Real Confejo de Hazienda. 


\section{CENSVRADE FREY LOPE deVega Carpio, del Abito de San Iuan.}

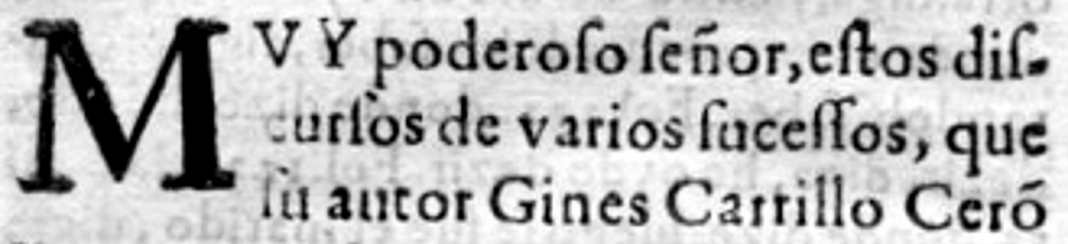
llama Nouelas, por mandadode V.A. he vilto, y no tiene cofa que ofenda, ni a nueftra SantaFè, ni a las coftumbres, es leccion encretenida, como muchos efcritores antiguos, y modernos efcrivieron para deł cytar, enfeñädo, a fsi en Francia el Bobiltan, y en Italia el Boca cio, cuyo eftilo no defdeńò Plutitarco, comofe véen la Eriftoclea, ni Helio. doro enfu Teagenes, afsi podrà V. A. ficadoleruido, dar licencia para fu im. prefsion, que efte es mi parecer. En Ma drid a 21 de Diziembre de 1632 años. Froy Lope deV ega Carpio.

PRO: 
¿os

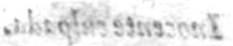

A FREY LOP E FELIX de Vega Carpio, del Abito de fan Iuan, Familiar del fanto Oficio de la Inquificion, Fifcal de la Ca. mara Apoftolica.

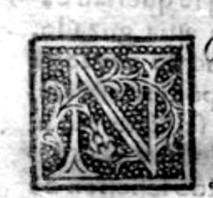

OSecomo me atreuo a dedicar a D.m.efta bumilde nouela, que intitulo, $S_{e}=$ gurda parte de los Perros de Maudes, que bizoch infigne Miguel de Zeruates Saauedri, fièdo v.mict Apolo, el Oraculo, el Fenix, el Virgilio de nueftros tiêpos, que a aner Edolo en los pafjados, le husieran leuanta do eftatuas, y es fuerça que a tales rayos. todo fedeslumbre: difculpanie el defeoq betenido de poderle Jeruir, y berle cnel puefto que merece, pues a mi Der no ballo

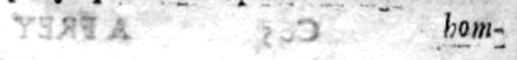

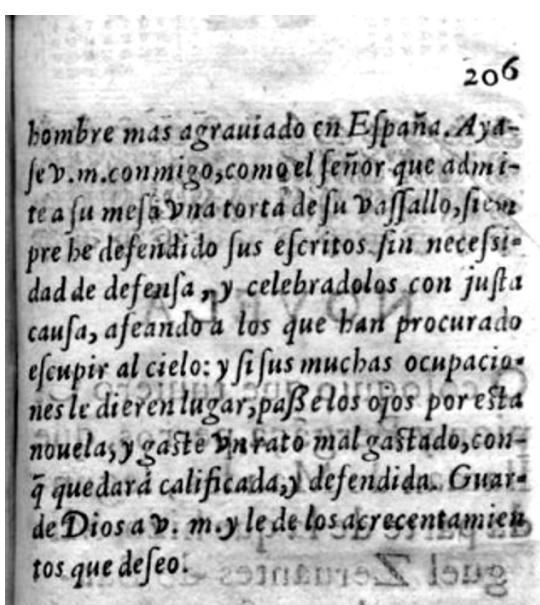

\section{Gines CarrilloCeron.} zelory

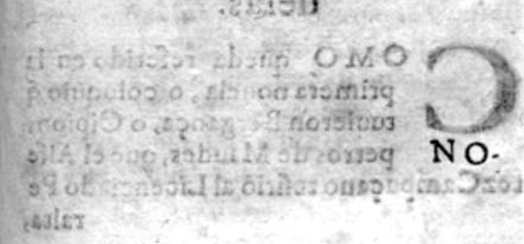




\section{BIBLIOGRAFÍA}

\section{1) Textos}

Cervantes, Miguel de, Novelas ejemplares, ed. de Jorge García López, estudio preliminar de Javier Blasco, Barcelona, Crítica, 2001.

Cervantes, Miguel de, Los trabajos de Persiles y Sigismunda, ed. Florencio Sevilla Arroyo; Antonio Rey Hazas, Alcalá de Henares, Centro de Estudios Cervantinos, 1994.

Collado del Hierro, Agustín, Granada (poema s. XVII), ed. de Carmen C. López Carmona, Jaén, Universidad de Jaén, 2005.

Henríquez De Jorquera, Francisco, Anales de Granada, ed. de Antonio Marín Ocete, Granada, Publicaciones de la Facultad de Letras, 1934, 2 vols.

Hidalgo, Gaspar Lucas, Diálogos de apacible entretenimiento, ed. Julio Alonso Asenjo y Abraham Madroñal, Valencia, Universitat de València, 2010.

LASSO DE LA VEGA, Luis, Tasa general de los precios a que se han de vender las mercaderías y las hechuras, salarios, jornales y demás cosas..., Granada, Imprenta de la Real Chancillería, 1627.

Sanz del Castillo Castillo, Mojiganga del gusto, ed. Emilio Cotarelo, Madrid, Bibliófilos Españoles, 1908.

Soons, Alan C., Haz y envés del cuento risible en el siglo de oro, Estudio y antología, Londres, Tamesis Books Ltd, 1976.

\section{2) Bibliografía crítica}

AlCALÁ, Ángel, Literatura y ciencia ante la Inquisición española, Madrid, Laberinto, 2001.

AlCAlde, Pilar, Estrategias temáticas y narrativas en la novela feminizada de María de Zayas, Newark, Juan de la Cuesta, 2005.

AlgABA, Nieves, «Inserción, función y estructura del relato breve: las Novelas a Marcia Leonarda de Lope de Vega», en Dicenda, n. ${ }^{\circ}$ 19, 2001, pp. 9-30.

Avalle-ArCe, Juan Bautista, Introducción a El peregrino en su patria, de Lope de Vega, Madrid, Castalia, 1973.

BALANCY, Elisabeth, Violencia civil en la Andalucia moderna (ss. XVI-XVII): familiares de la Inquisición y banderías locales, Sevilla, Universidad de Sevilla, 1999.

Bataillon, Marcel, Pícaros y picaresca, Madrid, Taurus, 1982.

Bonilla, Rafael, «Máscaras de seducción en las Novelas a Marcia Leonarda», Edad de Oro, XXVI, 2007, pp. 91-145.

BonILla, Rafael, Novelas cortas del siglo XVII, Madrid, Cátedra, 2010.

CABo Aseguinolaza, Fernando, Introducción a la edición del Buscón, Barcelona, Crítica, 1993.

Cejador y Frauca, Julio, Diccionario fraseológico del Siglo de Oro (Fraseología o estilística castellana), ed. Abraham Madroñal y Delfín Carbonell, Barcelona, Ediciones del Serbal, 2008.

Chevalier, Maxime, Quevedo y su tiempo: la agudeza verbal, Barcelona, Crítica, 1992.

Close, Anthony J., «Lo cómico y la censura en el siglo de Oro, II», Bulletin Hispanique, $105,{ }^{\circ}{ }^{\circ} 2,2003$, pp. 271-301.

Close, Anthony J., Cervantes and the Comic Mind of His Age, Oxford, Oxford UP, 2000.

CLOSE, Anthony J., «La dicotomía burlas/veras como principio estructurante de las novelas cómicas del Siglo de Oro», en I. Arellano \& Victoriano Roncero, eds., Demócrito áureo: los códigos de la risa en el Siglo de Oro, Sevilla, Editorial Renacimiento, 2006, pp. 113-142. 
COLÓN CALDERÓN, Isabel, «Humor y fábulas burlescas en la novela cortesana», en J. Huerta Calvo, E. Peral Vega, J. Ponce Cárdenas, eds., Tiempo de burlas, Madrid, Verbum, 2001, pp. 91-108.

COLÓN CALDERÓN, Isabel, La novela corta en el siglo XVII, Madrid, Laberinto, 2001.

Cotarelo, Emilio, «Un novelista del siglo XVII e imitador de, desconocido (Gines Carrillo Cerón)», BRAE, XII, 1925, pp. 640-661.

DíEZ FERNÁNDEZ, José Ignacio, "Viendo yo esta desorden del mundo»: textos literarios españoles de los siglos de oro en la Colección Fernán Núñez, Burgos, Fundación Instituto Castellano y Leonés de la Lengua, 2003.

Dana B. DraKe, Cervantes' Novelas ejemplares: a selective annotated bibliography, New York, Garland, 1981.

FERNÁNDEZ NiETO, Manuel, «Función de los géneros dramáticos en novelas y misceláneas», Criticón, n. ${ }^{\circ}$ 30, 1985, pp. 151-168.

García Gómez, Ángel María, Actividad teatral en Córdoba y arrendamientos de la Casa de las Comedias, London, Tamesis, 1999, p. 204.

GARCía LÓPEZ, Jorge (ed.), Novelas ejemplares, Barcelona, Círculo de Lectores, 2005.

GARRIDO ARDilA, Juan Antonio, El género picaresco en la crítica literaria, Madrid, Biblioteca Nueva, 2008.

Gil Albarracín, Antonio, Documentos sobre el real Monasterio de la Encarnación, Almería, GBG Editora, 1996.

GómEZ, Jesús, El diálogo en el Renacimiento español, Madrid, Cátedra, 1988.

GómEZ, Jesús, El diálogo renacentista. Madrid, Laberinto, 2000.

GonZÁlez DE AMEZÚA, Agustín, Cervantes creador de la novela corta en España, Madrid, CSIC, 1982.

KRÖMER, Wolfram, Formas de la narración breve en las literaturas románicas hasta 1700, Madrid, Gredos, 1979.

LACARRA, María Jesús, «"Del que olvidó la muger te diré la fazaña”. La historia de don Pitas Pajas desde el Libro de buen amor (estr.474-484) hasta nuestros días», Culturas Populares. Revista Electrónica, n. 5 (julio-diciembre 2007). «http://www.culturaspopulares.org/textos5/articulos/lacarra.htm>

LÁzAro CARreter, Fernando, Lazarillo de Tormes en la picaresca, Barcelona, Ariel, 1972.

LóPEZ-Huertas PÉrez, María José, Bibliografía de impresos granadinos de los siglos XVI y XVII, Granada, Universidad de Granada-Diputación Provincial de Granada, 1997, 3 vols.

MAdroñal, Abraham, «De grado y de gracias». Vejámenes universitarios de los Siglos de Oro, Madrid, CSIC, 2005.

Márquez Villanueva, Francisco, Trabajos y días cervantinos, Alcalá, CEC, 1995.

Moreno Romera, Bibiana, Artistas y artesanos del Barroco granadino, Granada, Universidad de Granada, 2001.

Navarro Durán, Rosa, La novela picaresca, Madrid, Fundación José Antonio Castro, 2005-2007.

Oltra TomÁs, Juan Miguel, La parodia como referente en La pícara Justina, León, Diputación de León, 1985.

Orozco, Emilio, El poema Granada de Collado del Hierro, Granada, Patronato de la Alhambra, 1964.

OrOzCO, Emilio, La literatura en Andalucía, ed. José Lara Garrido, Málaga, Universidad de Málaga, 2006.

PinTO CRESPO, Vicente, Inquisición y control ideológico en España, Madrid, Taurus, 1983. 
Rey Hazas, Antonio, Deslindes de la novela picaresca, Málaga, Universidad de Málaga, 2003.

Rico, Francisco, La novela picaresca y el punto de vista, Barcelona, Seix Barral, 2000.

Ripoll, Begoña, La novela barrroca, Salamanca, Universidad de Salamanca, 1991.

Rodríguez CuAdros, Evangelina, Novela corta marginada del siglo XVII español, Valencia, Universidad de Valencia, 1979.

SORIA MeSA, Enrique, «Burocracia y conversos. La Real Chancillería de Granada en los siglos XVI y XVII», en Francisco J. Aranda Pérez, Letrados, juristas y burócratas, Cuenca, Ediciones de la Universidad de Castilla-La Mancha, 2005, pp. 107-144.

VAíllo, Carlos, «La novela picaresca y otras formas narrativas», en Historia y crítica de la literatura española, III: Barroco, Barcelona, Crítica, 1983.

Recibido: 16 de agosto de 2011

Aceptado: 10 de octubre de 2011

\title{
Resumen
}

Se describe en el artículo el hallazgo de un libro que estaba perdido desde hace tiempo, las Novelas de varios sucesos (1635), de Ginés Carrillo Cerón. Dicho libro, que no se conserva más que en el ejemplar descrito, hoy en biblioteca particular, contiene ocho novelas, entre las que figura la continuación del cervantino Coloquio de los perros.

Palabras clave: Coloquio de los perros, Novelas ejemplares, Ginés Carrillo Cerón.

Title: The second lost part of Ginés Carrillo Cerón's El Coloquio de los perros

\begin{abstract}
The finding of the book that was lost for time is described in this article. It is about Ginés Carrillo Cerón's las Novelas de varios sucesos, which does not remain any more that in the described copy, today in a particular library. It contains eight novels, between which it appears the continuation of the cervantine Coloquio de los perros.
\end{abstract}

Key words: Coloquio de los perros, Novelas ejemplares, Ginés Carrillo Cerón. 